\title{
Curcuma zedoaria petroleum ether extract reverses the resistance of triple-negative breast cancer to docetaxel via pregnane $X$ receptor
}

\author{
En-Qi Qiao, Hong-Jian Yang, Xing-Fei Yu, Li-Jie Gong, Xi-Ping Zhang, Dao-Bao Chen \\ Department of Breast Tumor Surgery, Cancer Hospital of University of Chinese Academy of Sciences, Zhejiang Cancer Hospital, Hangzhou, China \\ Contributions: (I) Conception and design: DB Chen, EQ Qiao; (II) Administrative support: None; (III) Provision of study materials or patients: None; \\ (IV) Collection and assembly of data: XP Zhang, LJ Gong; (V) Data analysis and interpretation: XF Yu, EQ Qiao; (VI) Manuscript writing: All \\ authors; (VII) Final approval of manuscript: All authors. \\ Correspondence to: Dao-Bao Chen, MD. Chief Physician of Breast Surgery Department, Cancer Hospital of University of Chinese Academy of \\ Sciences, No. 1, Banshan East Road, Hangzhou 310022, China. Email: drdaobao@aliyun.com.
}

Background: Triple-negative breast cancer (TNBC) is characterized by its aggressiveness and poor prognosis. Docetaxel is the common chemotherapeutic drug used in the treatment of TNBC. However, resistance to docetaxel has limited the effectiveness of TNBC treatment. Petroleum ether extracts of Curcuma zedoaria (PECZ) can inhibit the proliferation of MDA-MB-231 cells. However, the effect of PECZ on docetaxel resistance is not clear.

Methods: A docetaxel-resistant MDA-MB-231 (MDA-MB-231/docetaxel) cell line was established, and Cell Counting Kit-8 (CCK-8), quantitative real-time PCR (qRT-PCR), and western blotting assays were used to evaluate the effect of docetaxel resistance in MDA-MB-231 cells. Next, CCK-8 was also performed to detect the effect of docetaxel or the combination treatment of docetaxel and PECZ on the proliferation of MDA-MB-231/docetaxel cells. Thereafter, MDA-MB-231/docetaxel cells were subcutaneously injected into nude mice to induce a TNBC xenograft model, and the mice were divided into a model group, docetaxel group, PECZ group, and combination of docetaxel and PECZ group. Subsequently, hematoxylin and eosin (HE) staining, immunohistochemical, qRT-PCR, and western blotting were used to estimate the effect of pre-treatment with PECZ on docetaxel tolerance reversal.

Results: PECZ significantly inhibited the expression of pregnane $\mathrm{X}$ receptor (PXR), multidrug resistance 1 (MDR1), breast cancer resistance protein (BCRP), and cytochrome P-450 (CYP3A4) in MDA-MB-231/ docetaxel cells. Only higher concentrations of docetaxel could inhibit the viability of MDA-MB-231/ docetaxel cells. When pre-treated with PECZ, lower concentrations of docetaxel could significantly inhibit cell viability. Meanwhile, combination treatment also reduced the tumor volume, ameliorated the pathological change of tumor tissues, and down-regulated the expressions of PXR, MDR1, BCRP, and CYP3A4 (according to HE staining, immunohistochemical, qRT-PCR and western blotting results in vivo).

Conclusions: Our research showed that PECZ reversed docetaxel resistance in TNBC by PXR both in vitro and in vivo, which provides the basis for further investigations into the potential therapeutic impact of docetaxel resistance in TNBC.

Keywords: Triple-negative breast cancer (TNBC); MDA-MB-231; rhizoma zedoaria petroleum ether extract; docetaxel-resistant

Submitted Jul 23, 2021. Accepted for publication Sep 02, 2021.

doi: $10.21037 / \mathrm{atm}-21-4199$

View this article at: https://dx.doi.org/10.21037/atm-21-4199 


\section{Introduction}

Breast cancer is one of the most common malignant tumors in women, and seriously threatens their health and lives (1). Triple-negative breast cancer (TNBC) is the most refractory and poor-prognosis type of breast cancer due to high histological grade, high degree of malignancy, high recurrence, and metastasis (2,3). Surgery, radiotherapy, and chemotherapy are the main therapies for TNBC because it is not sensitive to hormones and has no targeted therapy (4). At present, docetaxel is the most accessible and effective chemotherapeutic drugs for the treatment of TNBC (5). However, docetaxel tolerance has limited its therapeutic effect in TNBC and resulted in treatment failure (6). Currently, there are six known mechanisms of TNBC resistance, including the pumping of chemotherapy drugs from tumor cells by ATP binding cassette (ABC) transporter, overexpressed $\beta$-tubulin III subgroup induced paclitaxel resistance, DNA repair enzyme mutations lead to decreased sensitivity of tumor cells to chemotherapeutic drugs, the gene mutation involved in normal cell apoptosis inhibited chemotherapy-induced apoptosis of tumor cells, the effects of acetaldehyde dehydrogenase 1 (ALDH1) and glutathione/glutathione-s-transferase lead to inactivation or degradation of chemotherapeutic drugs, and effect of nuclear transcription factor-kappa $\mathrm{B}(\mathrm{NF}-\kappa \mathrm{B})$ signaling pathway on chemotherapy (7). Therefore, docetaxel resistance in TNBC treatment remains a challenge to be overcome. To this end, many studies have been carried out in the medical community. Wang et al. found that MA can directly inhibit the expression and interaction between MELK and FoxM1 as well as the transcriptional activity of FoxM1, thus reducing the expression of ABCB1. In human TNBC therapy, the combination of DOC and MA may help overcome DOC resistance (8). Previous studies have shown that plants and plant-derived compounds, such as curcuma zedoaria, play an important role in cancer $(9,10)$. Curcuma zedoaria plays a positive role in many diseases, including rectal, lung, liver, gastric, and cervical cancers (11). It also exerts anti-thrombosis, anti-platelet aggregation, anti-atherosclerosis, blood lipid regulation effects (11). Moreover, the petroleum ether extracts of Curcuma zedoaria (PECZ) have been shown to inhibit the proliferation of MDA-MB-231 cells (12). However, the mechanism of PECZ and whether PECZ can reverse docetaxel tolerance in TNBC remains unclear.

Therefore, we established a docetaxel-resistant MDAMB-231 (MDA-MB-231/docetaxel) cell line to evaluate the effect of $\mathrm{PECZ}$ in reversing docetaxel resistance in vitro. The MDA-MB-231/docetaxel cells were then subcutaneously injected into nude mice to investigate the effect of PECZ in vivo. According to our results, PECZ can induce the expression of drug resistance genes, inhibit tumor growth, and ameliorate the pathological changes of tumor tissue. These findings provide a basis for further investigating TNBC resistance reversal.

Nowadays integrated Chinese and western medicine is becoming one of the important means to treat cancer, and the value of Chinese medicine in treating cancer has been paid more and more attention by the world. This study will further confirm the feasibility of petroleum ether extract from Curcuma zedoary as an anti-tumor drug, and provide some theoretical basis for the development of Chinese herbal plant active extract as an anti-tumor innovative drug. We present the following article in accordance with the ARRIVE reporting checklist (available at https://dx.doi. org/10.21037/atm-21-4199).

\section{Methods}

\section{Preparation of PECZ}

Curcuma zedoaria (40 g) was crushed into coarse particles and soaked in $70 \%$ ethanol overnight. After extraction twice by thermal reflux, the extracted solution was combined and concentrated under decompression. When the ethanol was completely volatilized, the extracted solution was extracted by aether petrolei. The petroleum ether extracts were cold dried and weighed three times to calculate the mean value. Finally, after filtration and sterilization, the extract was concentrated and stored at $4{ }^{\circ} \mathrm{C}$.

When PECZ was used, $5 \mathrm{mg}$ PECZ was dissolved in $500 \mu \mathrm{L}$ dimethyl sulfoxide and filtered using a $0.22 \mu \mathrm{m}$ filter membrane. Next, the medium was used to dilute the extracting solution to a desired concentration before use.

\section{Construction of docetaxel-resistant MDA-MB-231 cell lines}

MDA-MB-231 cells were purchased from Sabine Biotechnology Co., Ltd. (Shanghai, China). The cells were maintained in Roswell Park Memorial Institute-1640 (RPMI-1640) medium supplemented with $100 \mathrm{U} / \mathrm{mL}$ streptomycin and $100 \mu \mathrm{g} / \mathrm{mL}$ penicillin, $10 \%$ fetal bovine serum (FBS), and cultured under a humidified atmosphere containing $5 \% \mathrm{CO}_{2}$ at $37{ }^{\circ} \mathrm{C}$. In detail, the MDA-MB-231 
cells were continuously exposed to an ascending series of docetaxel $(0.0156,0.0313,0.0625,0.125$, and $0.25 \mu \mathrm{g} / \mathrm{mL}$ ) to induce docetaxel-resistant cells (MDA-MB-231/ docetaxel) (13).

\section{CCK-8 assay}

Firstly, a CCK-8 (HY-K0301, MCE, USA) was utilized to determine the MDA-MB-231/docetaxel cell proliferation rates. According to the manufacturer's instructions, MDAMB-231/docetaxel cells $\left(2 \times 10^{4} / \mathrm{mL}, 100 \mu \mathrm{L} /\right.$ well; the individual well was considered the experimental unit in this study) were transferred into a 96-well plate and cultured until the cells were fully attached. Subsequently, MDA-MB-231/ docetaxel cells were exposed to gradient concentrations of PECZ $(100,200,300,400$, and $500 \mu \mathrm{g} / \mathrm{mL})$ for $24 \mathrm{~h}$, and cultured with CCK- 8 solution $(10 \mu \mathrm{L})$ for $2 \mathrm{~h}$. The absorbance of each experimental group was measured at $450 \mathrm{~nm}$.

Subsequently, CCK- 8 was performed to detect the effect of docetaxel or docetaxel combined with PECZ on the proliferation of MDA-MB-231/docetaxel cells. Firstly, MDA-MB-231/docetaxel cells $\left(2 \times 10^{4} / \mathrm{mL}, 100 \mu \mathrm{L} /\right.$ well; the individual well was considered the experimental unit in this study) were cultured in RPMI-1640 medium containing (or not) $100 \mu \mathrm{g} / \mathrm{mL} \mathrm{PECZ} \mathrm{for} 24 \mathrm{~h}$. Next, the medium was replaced with fresh medium containing various concentrations of docetaxel $(0.1,0.2,0.4,0.6,0.8,1.6$, and $3.2 \mu \mathrm{g} / \mathrm{mL}$ ) for $12 \mathrm{~h}, 24 \mathrm{~h}$, and $48 \mathrm{~h}$, respectively. After incubation with the CCK-8 solution $(10 \mu \mathrm{L})$ for $2 \mathrm{~h}$, each experimental group was also measured at $450 \mathrm{~nm}$ to obtain the absorbance.

\section{Tumor xenograft model and treatment}

Forty-eight BALB/c nude mice (6-8 weeks, $18-20$ g body weight) were purchased from the Centre of Experimental Animals at the Shanghai SLAC Laboratory Animal Co., Ltd. (Shanghai, China) [reference number Certificate No. SCXK (Hu) 2017-0005]. All mice were kept in an environment where the ambient temperature was maintained at $22-23{ }^{\circ} \mathrm{C}$, the relative humidity was $45-50 \%$, and a 12/12-hour light cycle. The mice were then randomly divided into the following four groups (12 mice/group; the individual mouse was considered the experimental unit in this study): model, PECZ, docetaxel, and the combination of PECZ and docetaxel groups. The health status of the mice was monitored every 2 weeks to exclude problematic mice from the study.

After adaptive feeding for a week, MDA-MB-231/ docetaxel cells in logarithmic growth phase $\left(4 \times 10^{6}\right.$ cells $)$ were suspended in $0.2 \mathrm{~mL}$ RPMI 1640 medium and subcutaneously injected into the right flank of nude mice. When the tumors reached $100 \mathrm{~mm}^{3}$, the mice were treated with PECZ $(10 \mathrm{mg} / \mathrm{mL}, 0.2 \mathrm{~mL})$, docetaxel $(2.5 \mathrm{mg} / \mathrm{kg}$ docetaxel dissolved in 0.2 normal saline), or the combination of PECZ and docetaxel $(10 \mathrm{mg} / \mathrm{mL} \mathrm{PECZ} \mathrm{and} 2.5 \mathrm{mg} / \mathrm{kg}$ docetaxel dissolved in 0.2 normal saline) by intraperitoneal injection once daily and consistent for 20 consecutive days . Tumor volumes of $>$ or $<100 \mathrm{~mm}^{3}$ were excluded. After the last administration, the tumor size was measured and calculated as follows: tumor volume $\left(\mathrm{mm}^{3}\right)=\mathrm{L}_{1} \times\left(\mathrm{L}_{2}\right)^{2}$ $\times 0.5236$, where $\mathrm{L}_{1}$ represents the long diameter and $\mathrm{L}_{2}$ represents the short diameter. The maximum size that tumors were allowed to grow in the mice before euthanasia was $2,000 \mathrm{~mm}^{3}$. Experiments were performed under a project license [No.: SYXK (Zhe) 2020-0024] granted by ethics board of Hangzhou Eyong Biotechnological Co., Ltd. Animal Experiment Center (Zhejiang, China), in compliance with National Institutes of Health Guide for the Care and Use of Laboratory Animals. A protocol was prepared before the study without registration.

For each animal, further studies were estimated by investigators who were unaware of the treatment of mice. In this study, the mice did not show any other adverse events, and had no abnormal tissues when autopsied except for the tumor tissue.

\section{Hematoxylin and eosin (HE) staining}

After the last administration, all of the mice were sacrificed and the tumors were excised. Briefly, the tumor tissues were fixed in $10 \%$ neutral formalin, then dehydrated by gradient ethanol, embedded, and cut into $4 \mu \mathrm{m}$ sections. Lastly, the tumor tissues were stained with $\mathrm{HE}$ and observed under a light microscope (Leica, Germany).

\section{Immunobistochemical}

Immunohistochemistry stains were performed to detect the expression of PXR, MDR1, CYP3A4, and BCRP in tumor tissues. Briefly, after deparaffinization and rehydration, the paraffin-embedded slides were extracted in citric acid buffer $(0.1 \mathrm{~mol} / \mathrm{L}, \mathrm{PH}=6.0)$ and treated with $3 \% \mathrm{H}_{2} \mathrm{O}_{2}$. The slides were then incubated with primary antibodies overnight at $4{ }^{\circ} \mathrm{C}$. After washing, biotinylated secondary antibodies 
Table 1 Primer sequence of the genes for qRT-PCR analysis (5'-3')

\begin{tabular}{lrr}
\hline Gene & Forward primer & Reverse primer \\
\hline PXR & CGAGCT CCG CAG CATCA & TGTATG TCC TGGATG CGCA \\
MDR1 & CCATAGCTCGTGCCCTTGTTAGA & CGGTGAGCAATCACAATGCAG \\
BCRP & TCCACTGCTGTGGCATTAAA & TGCTGAAACACTGGTTGGTC \\
CYP3A4 & GATTGACTCTCAGAATTCAAAAGAAACTGA & GGTGAGTGGCCAGTTCATACATAATG \\
$\beta$-actin & TTCTACAATGAGCTGCGTGTG & CAGCCTGGATAGCAACGTACA \\
\hline
\end{tabular}

PXR, pregnane X receptor; MDR1, multidrug resistance 1; BCRP, breast cancer resistance protein; CYP3A4, cytochrome P-450.

were added and incubated at room temperature for $20 \mathrm{~min}$. Finally, the sections were stained with a DAB to develop the color and counter-stained with hematoxylin. The primary antibodies included the following: PXR antibody (1:50, 15607-1-AP, Proteintech, USA), MDR1 antibody (1:50, AF5185, Affinity, USA), BCRP antibody (1:50, AF5177, Affinity, USA), and CYP3A4 antibody (1:50, 18227-1-AP, Proteintech, USA).

\section{Quantitative real-time PCR ( $q R T-P C R)$}

After different treatments, the MDA-MB-231/docetaxel cells and tumor tissues were extracted using TRIzol reagent (B511311; Shenggong Biotech, Inc., Shanghai, China) to obtain the total RNA. The total RNA was then reverse transcribed to cDNA and detected by qRT-PCR with a SYBR Green kit. Table 1 shows the primer sequences of PXR, MDR1, BCRP, CYP3A4, and $\beta$-actin. The relative mRNA expression levels were calculated by the $2^{-\Delta \Delta C t}$ method and normalized the level of target genes relative to $\beta$-actin.

\section{Western blotting}

The proteins of MDA-MB-231/docetaxel cells and tumor tissues were extracted by RIPA lysis buffer (Phenylmethanesulfonyl fluoride). After centrifugation at $12,000 \mathrm{rpm}$ and $4{ }^{\circ} \mathrm{C}$ for $15 \mathrm{~min}$, the protein concentration was detected by BCA kit (pc0020, Solarbio). SDS-PAGE and a PVDF membrane were used to separate and transfer the protein. After blocking with $5 \%$ non-fat milk, the membranes were incubated with the primary antibodies, including PXR antibody (1:500, 15607-1-AP, Proteintech, USA), MDR1 antibody (1:500, AF5185, Affinity, USA), BCRP antibody (1:500, AF5177, Affinity, USA), CYP3A4 antibody (1:1,000, 18227-1-AP, Proteintech, USA), and $\beta$-actin antibody (1:1,000, M1210-2, HuaBio, China) at $4{ }^{\circ} \mathrm{C}$ overnight. They were then incubated with secondary antibodies at room temperature for $2 \mathrm{~h}$. After washing with tris buffered saline tween (TBST), the membrane was detected. The images were obtained and analyzed by Image J software (Macintosh-based National Institutes of Health, USA) to obtain the expressions of PXR, MDR1, BCRP, and CYP3A4.

\section{Statistical analysis}

The statistical analyses were performed using SPSS15.0 (IBM Corp., Armonk, NY, USA). Measurement data were expressed as $\bar{x} \pm$ s. The least significant difference (LSD) in one-way ANOVA was used to compare two groups. Each experiment step is repeated three times. $\mathrm{P}$ values $<0.05$ were considered statistically significant.

\section{Results}

\section{In vitro assay}

Effect of PECZ on the proliferation of MDA-MB-231/ docetaxel cells

In order to determine the effect of PECZ on the drug resistance cells MDA-MB-231/docetaxel, CCK-8 was performed to detect the proliferation of MDA-MB-231/ docetaxel cells. Compared with the untreated MDAMB-231/docetaxel cells, the proliferation of MDAMB-231/docetaxel cells was inhibited by PECZ in a dosedependent manner (Figure 1, $\mathrm{P}<0.05, \mathrm{P}<0.01$ ). These results suggested that PECZ could reverse the tolerance of MDAMB-231 to docetaxel.

\section{Effect of PECZ on the mRNA expression of drug} resistance genes

The effect of PECZ on the resistance-related mRNA 
expressions in MDA-MB-231/docetaxel cells was assessed by qRT-PCR. As demonstrated in Figure 2, compared with control group, as the concentration of PECZ increased, the mRNA expressions of PXR, MDR1, BCRP, and CYP3A4 were down-regulated in a dose-dependent manner $(\mathrm{P}<0.05$,

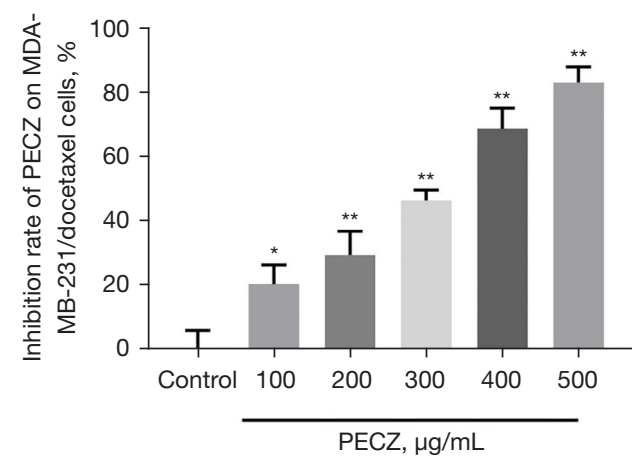

Figure 1 Effect of PECZ on the proliferation of MDA-MB-231/ docetaxel cells. $(\bar{x} \pm s, \mathrm{n}=3),{ }^{*}, \mathrm{P}<0.05 ;{ }^{* *}, \mathrm{P}<0.01$ vs. control group. PECZ, petroleum ether extracts of Curcuma zedoaria.
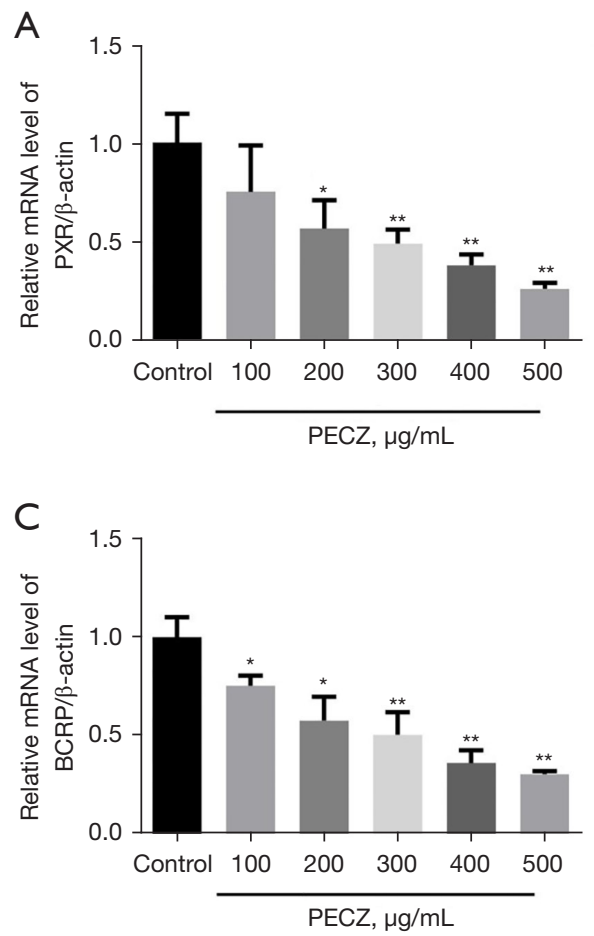

$\mathrm{P}<0.01)$

Effect of PECZ on the protein expression of drug resistance genes

The effect of PECZ on the resistance-related protein expressions in MDA-MB-231/docetaxel cells was assessed by western blotting. Consistent with the qRT-PCR results, compared with control group, the protein expressions of PXR, MDR1, BCRP, and CYP3A4 were also downregulated in $\mathrm{PECZ}$ treatment group in a dose-dependent manner (Figure 3, $\mathrm{P}<0.05, \mathrm{P}<0.01$ ).

\section{Tolerance reversal of MDA-MB-231/docetaxel cells}

In order to further estimate the reverse effect of PECZ and the inhibition of docetaxel on the MDA-MB-231/ docetaxel cells, a CCK-8 assay was performed again in the different treatment groups. Without PECZ treatment, the viability of MDA-MB-231/docetaxel cells cultured in a low concentration of docetaxel $(0.1$ and $0.2 \mu \mathrm{g} / \mathrm{mL})$ for 12 , 24, or $48 \mathrm{~h}$ was maintained. Only higher concentrations of
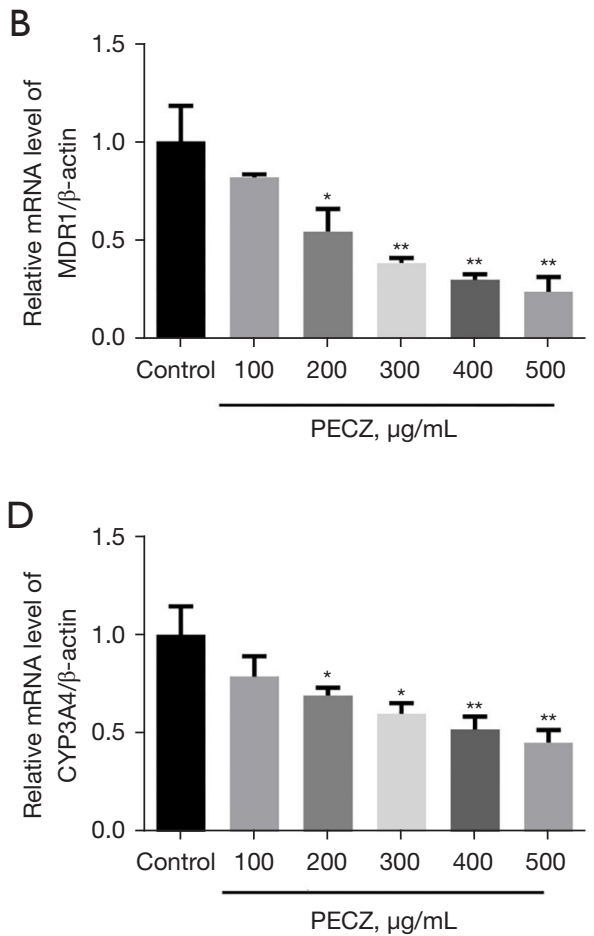

Figure 2 Effect of PECZ on the mRNA expression of drug resistance genes. The mRNA expressions of PXR (A), MDR1 (B), BCRP (C), and CYP3A4 (D) in MDA-MB-231/docetaxel cells were detected by qRT-PCR. ( $\bar{x} \pm \mathrm{s}, \mathrm{n}=3),{ }^{*}, \mathrm{P}<0.05$; **, $\mathrm{P}<0.01$ vs. control group. PECZ, petroleum ether extracts of Curcuma zedoaria; PXR, pregnane X receptor; MDR1, multidrug resistance 1; BCRP, breast cancer resistance protein; CYP3A4, cytochrome P-450. 

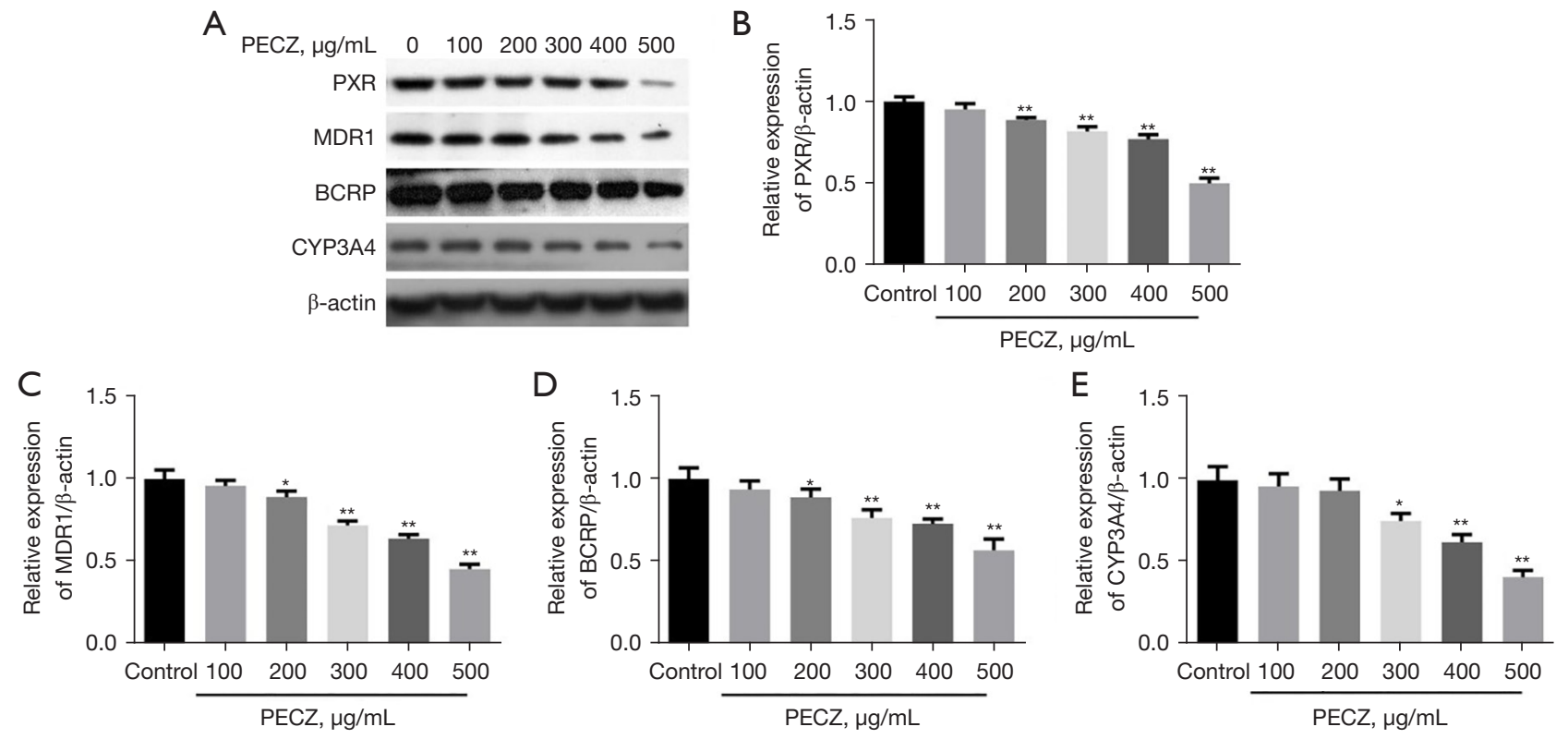

Figure 3 Effect of PECZ on the protein expression of drug resistance genes in MDA-MB-231/docetaxel cells. Representative band of each protein (A). Relative protein expression of PXR (B), MDR1 (C), BCRP (D), and CYP3A4 (E). ( $\bar{x} \pm \mathrm{S}, \mathrm{n}=3),{ }^{*}, \mathrm{P}<0.05 ;{ }^{* *}, \mathrm{P}<0.01$ vs. control group. PECZ, petroleum ether extracts of Curcuma zedoaria; PXR, pregnane X receptor; MDR1, multidrug resistance 1; BCRP, breast cancer resistance protein; CYP3A4, cytochrome P-450.

docetaxel could significantly inhibit cell viability (Figure $4 A$, $\mathrm{P}<0.05, \mathrm{P}<0.01)$. However, when MDA-MB-231/docetaxel cells were pre-treated with PECZ, lower concentrations of docetaxel could significantly inhibit cell viability (Figure $4 B$, $\mathrm{P}<0.05, \mathrm{P}<0.01$ ), which suggested that $\mathrm{PECZ}$ can reverse of the tolerance of MDA-MB-231/docetaxel cells.

\section{The inbibitory effect of PECZ on tumor growth in the tumor xenograft model}

After treatment with PECZ and docetaxel (alone or combined), the tumor size was measured. As shown in Figure 5, after administration for 20 days, the tumor volume in the treatment groups were all lower than the model group, but treatment with PECZ alone showed no significant difference. However, treatment with docetaxel and the combination of PECZ and docetaxel could both significantly reduce the tumor volume $(\mathrm{P}<0.05)$.

\section{Treatment with PECZ and docetaxel ameliorated the pathological changes of tumor tissues}

The changes of tumor tissues in each group were detected by HE staining (Figure 6). The tumor cells showed active growth, dense cells, disordered arrangement in each group tumor tissues. Meanwhile, large and deep nuclei, and nuclear division could be seen in tumor cells under high magnification. Compared with the model group, the density of blood vessels and nuclear division was decreased obviously in the administration group. Moreover, the ameliorating effect of the combined PECZ and docetaxel treatment on the tumor tissue was better than treatment with PECZ or docetaxel alone.

\section{Combination of PECZ and docetaxel decreased the expression of PXR, MDR1, CYP $3 A 4$, and BCRP}

Immunohistochemistry was used to detect the expression of drug resistance genes in the different treatment groups (Figure 7). In the model group, the positive expressions of PXR, MDR1, CYP3A4, and BCRP were significantly higher than that in other groups. After the combination treatment of PECZ and docetaxel, the positive expressions of PXR, MDR1, CYP3A4, and BCRP were markedly decreased. Also, the inhibition of the positive expressions of drug resistance genes was stronger in the PECZ and docetaxel co-treatment group compared to treatment with PECZ or docetaxel individually. 

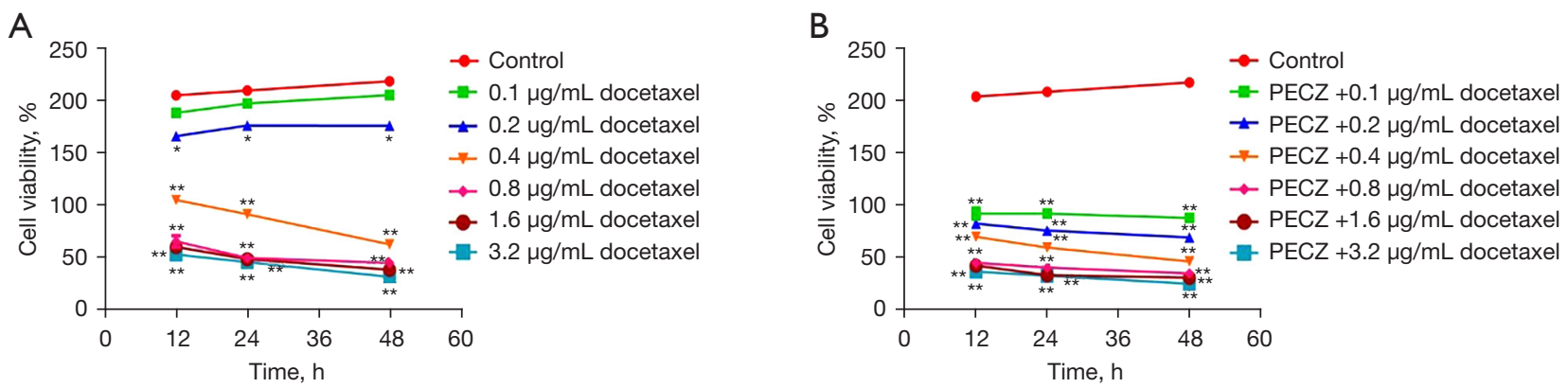

Figure 4 Reverse of the tolerance of MDA-MB-231/docetaxel cells. (A) Effect of docetaxel on the viability of MDA-MB-231/docetaxel cells without treatment with PECZ. (B) Effect of docetaxel on the viability of MDA-MB-231/docetaxel cells after treatment with PECZ. $(\bar{x} \pm$, $\mathrm{n}=3),{ }^{*}, \mathrm{P}<0.05$; **, $\mathrm{P}<0.01$ vs. control group. $\mathrm{PECZ}$, petroleum ether extracts of Curcuma zedoaria.

A

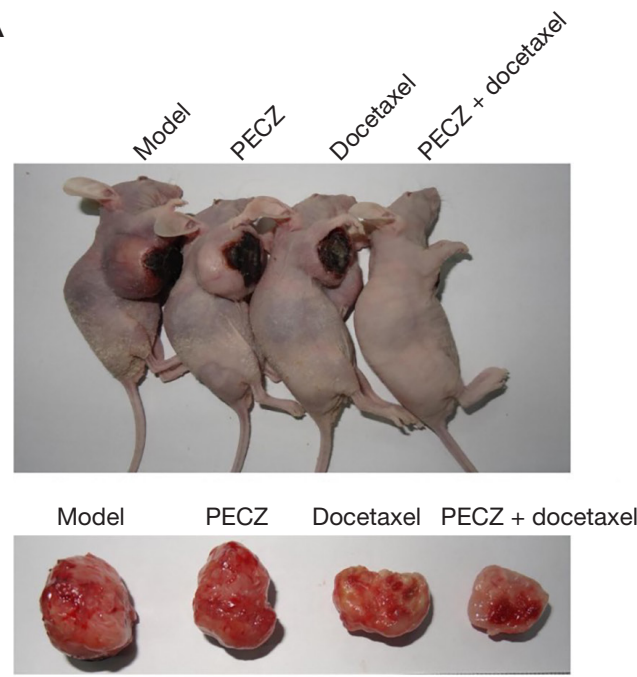

B

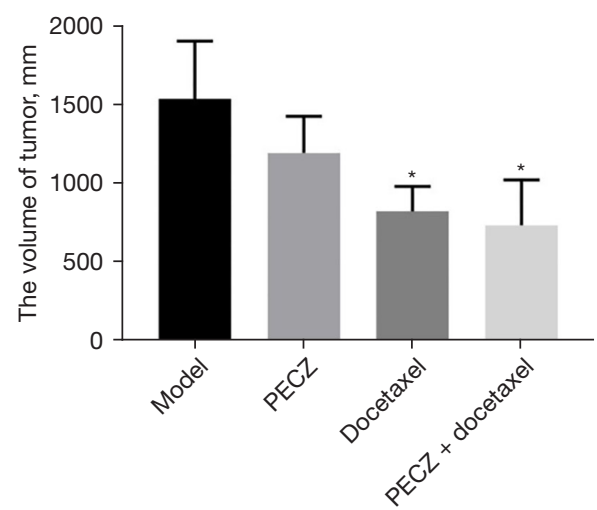

Figure 5 The inhibition effect of PECZ on tumor growth in tumor xenograft model. (A) Representative images of the tumor in each group of mice. (B) The tumor volume of the different treatment groups. $(\bar{x} \pm \mathrm{s}, \mathrm{n}=12),{ }^{*}, \mathrm{P}<0.05$ vs. model group.

\section{PECZ reduced the mRNA and protein expressions of PXR, MDR1, CYP3A4, and BCRP}

In order to further confirm the reversal effect of PECZ, qRT-PCR, and western blotting was also performed to detect the mRNA and protein expression in tumor tissues (Figure 8). The results suggested that the mRNA and protein expressions of PXR, MDR1, CYP3A4, and BCRP were markedly reduced in the combined PECZ and docetaxel treatment group $(\mathrm{P}<0.05, \mathrm{P}<0.01)$. Meanwhile, docetaxel significantly increased the protein expression levels of PXR, MDR1, CYP3A4, and BCRP in tumor tissues $(\mathrm{P}<0.05, \mathrm{P}<0.01)$, which indicated that $\mathrm{PECZ}$ can reverse the tolerance of docetaxel.

\section{Discussion}

Breast cancer is the main cause of cancer-related death among women worldwide (14). As one of the special subtypes of breast cancer, TNBC is insensitive to the clinically effective treatments of other types breast cancer (15). At present, paclitaxel and docetaxel have been shown to be efficient microtubule-poisoning drugs for the treatment of TNBC (16). However, the resistance to docetaxel usually appears in the progress of the TNBC treatment and reduces the treatment effect (17). Therefore, this study detected the mechanism of PXR-mediated PECZ reversal of the resistance of docetaxel in TNBC.

It is well known that Curcuma zedoaria is a common 

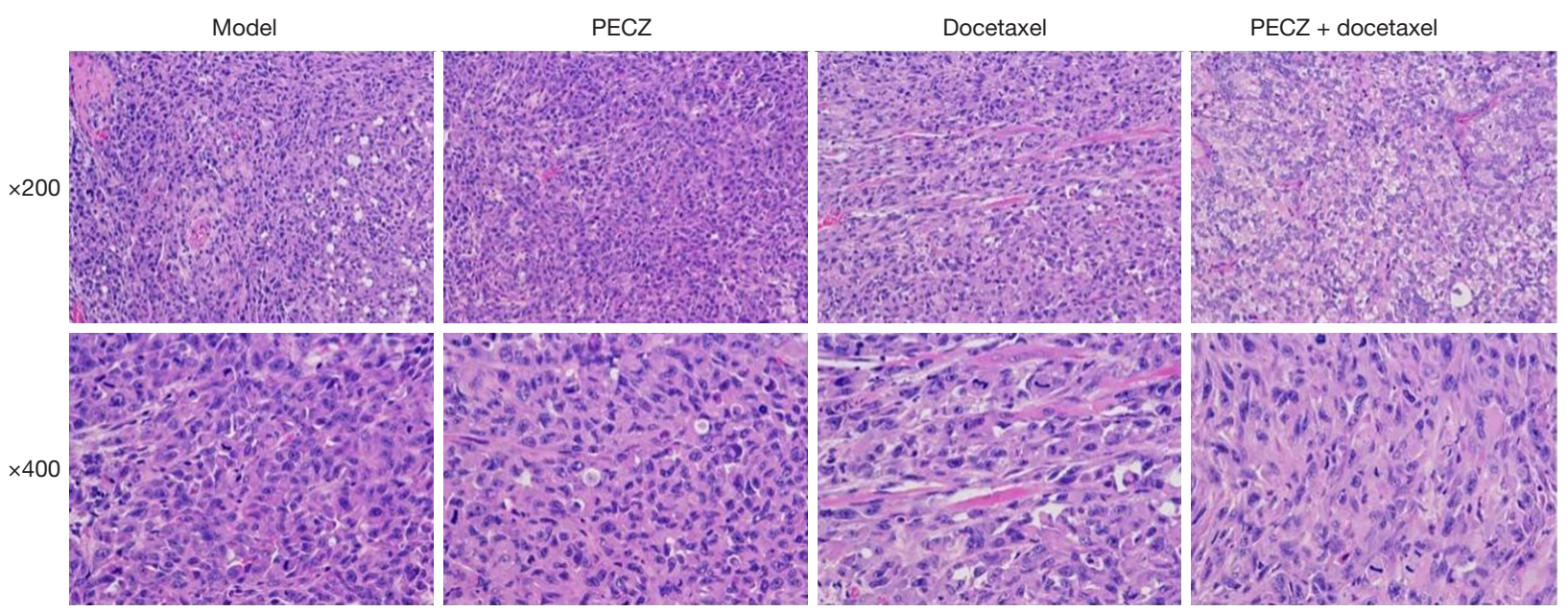

Figure 6 Representative HE staining images of tumor tissues in each group (original magnification $\times 200, \times 400) ;(\bar{x} \pm s, n=3)$.

chemotherapy drug for cancer-related diseases, such as cervical, colon, and especially breast cancers (18). It has been shown that PECZ possesses the strongest inhibitory effect on MDA-MB-231 cells compared to other extracts (12). Consistent with these results, we also found that the proliferation of MDA-MB-231/docetaxel cells was markedly inhibited after pre-treatment with PECZ. Meanwhile, the pathological changes of tumor tissue were also obviously ameliorated by pre-treatment with PECZ and treatment with docetaxel. PXR can regulate the expression of resistance-related genes to improve the metabolism and clearance of chemotherapeutic drugs in human cancer cells $(19,20)$, and plays a key role in breast cancer (21). In this study, the expression of PXR was increased in the MDA-MB-231/docetaxel cell group and mice with tumor xenograft. After pre-treatment with PECZ, the expression of PXR decreased both in vivo and in vitro after subsequent treatment with docetaxel, which showed that PECZ could effectively reverse the resistance of docetaxel in TNBC.

The bioavailability of chemotherapy drugs in cancer cells critically affects the efficiency of cancer treatment (22). When cancer cells possess drug resistance, the overexpression of MDR1 and CYP3A4 promotes the efflux and metabolism of various drugs and further induces reduced accumulation of the chemotherapeutic drugs in cancer cells (23). BCRP, as the breast cancer resistance protein and crucial marker of side population cells, also plays an important role in drug resistance (24). Therefore, it effectively reduces the efflux and metabolism of various drugs for the inhibition of resistance (25). Similarly, after pre-treatment with PECZ, the expression of MDR1,
BCRP, and CYP3A4 was decreased both in vivo and in vitro after subsequent treatment with docetaxel. However, without pre-treatment with PECZ, the expressions of PXR, MDR1, BCRP, and CYP3A4 were increased both in vivo and in vitro. These results also suggested that PECZ could effectively reverse the resistance of docetaxel in TNBC.

There may be other mechanisms involved in PECZ reversing docetaxel resistance in triple-negative breast cancer cells. For example, $\mathrm{Li}$ et al. found that $\beta$-elemene (the main component of PECZ) makes platinumresistant ovarian cancer cells more sensitive to platinum compounds and increases the anti-tumor proliferation effect of platinum compounds. The mechanism is mainly that $\beta$-elemene reduces cyclin $\mathrm{B} 1$ and $\mathrm{Cdc} 2$, thus making the cell cycle stay in G2 /M phase (26). Li et al. found that $\beta$-elemene significantly increased the activity of platinuminduced caspase, including caspase- $3,7,8,9,10$, in bladder cancer cells that were added with both platinum compound and $\beta$-elemene, compared with the control group that was added with platinum compound alone. This suggests that $\beta$-elemene can increase the cytotoxicity of platinum compounds through this signaling pathway and increase the sensitivity of bladder cancer cells to platinum compounds (27). However, the existence of these mechanisms in breast cancer needs further study.

\section{Conclusions}

In this study, we estimated the reversal effect of PECZ for docetaxel resistance in vivo and in vitro. Our results demonstrated that pre-treatment with PECZ could 


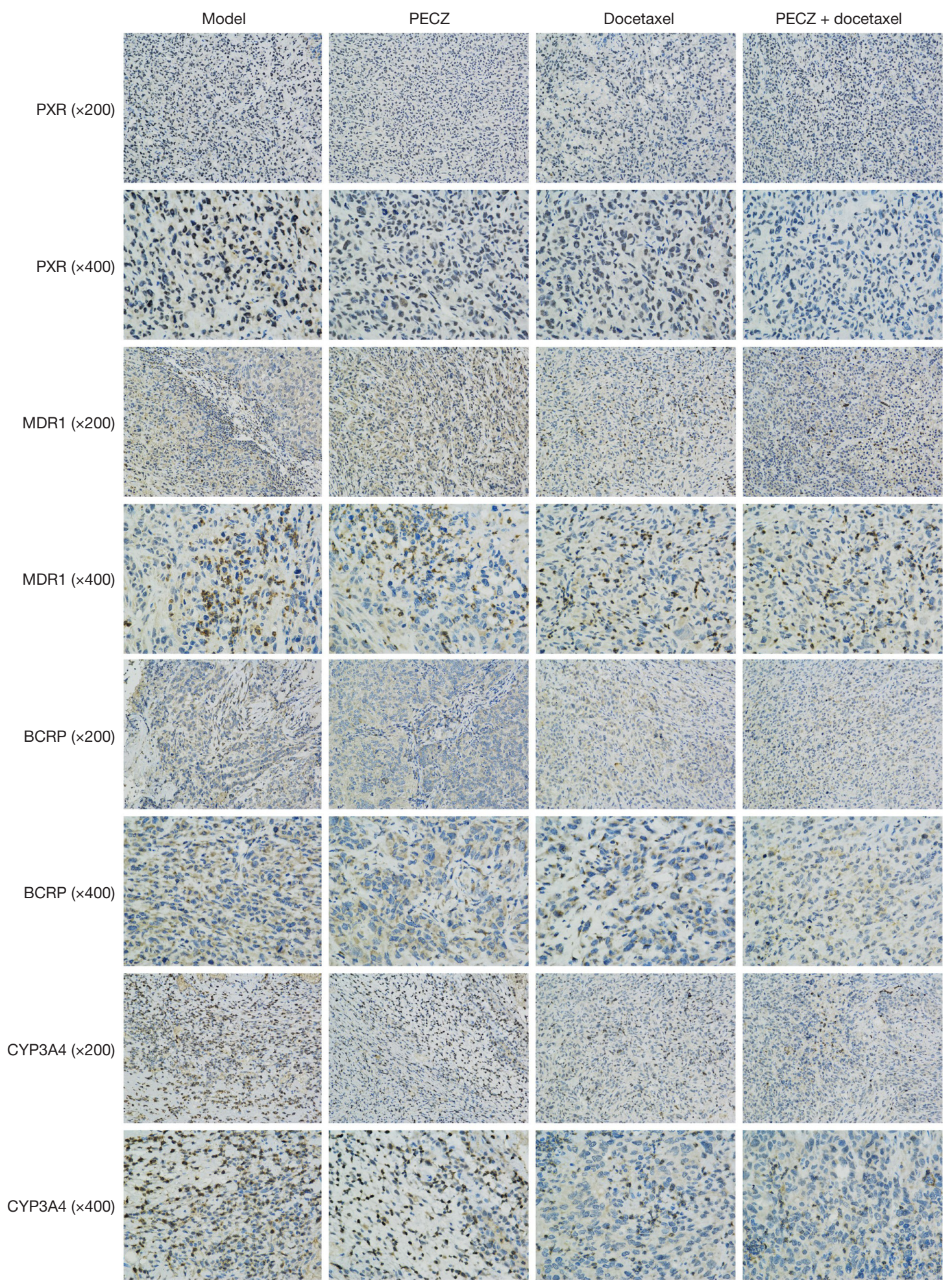

Figure $7 \mathrm{PECZ}$ and docetaxel decreased the expression of drug resistance genes. Representative images of immunohistochemical showing PXR, MDR1, CYP3A4, and BCRP in tumor tissues in the different groups. Original magnification $\times 200, \times 400 ;(\bar{x} \pm \mathrm{s}, \mathrm{n}=3)$. PECZ, petroleum ether extracts of Curcuma zedoaria; PXR, pregnane X receptor; MDR1, multidrug resistance 1; BCRP, breast cancer resistance protein; CYP3A4, cytochrome P-450. 


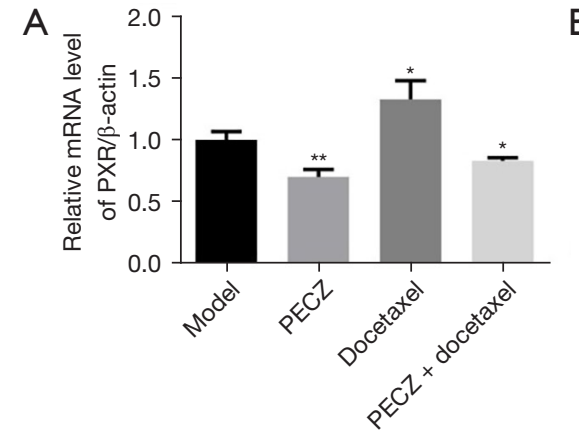

$\mathrm{D}$

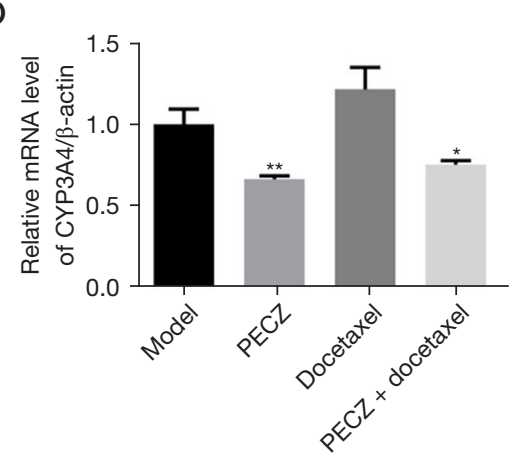

G

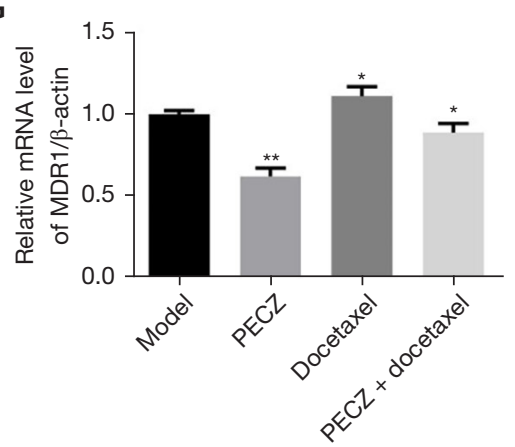

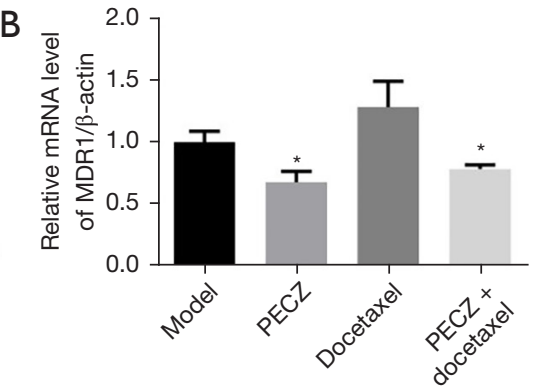

$E$

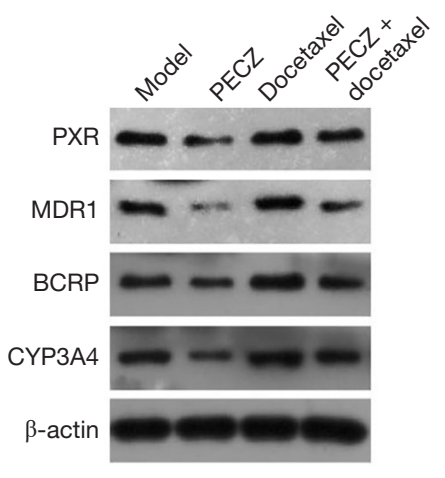

$\mathrm{H}$

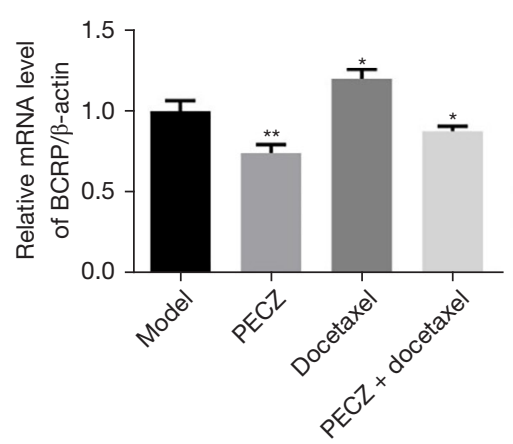

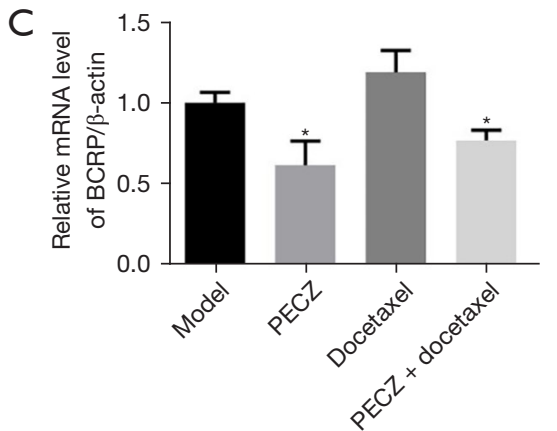

$\mathrm{F}$

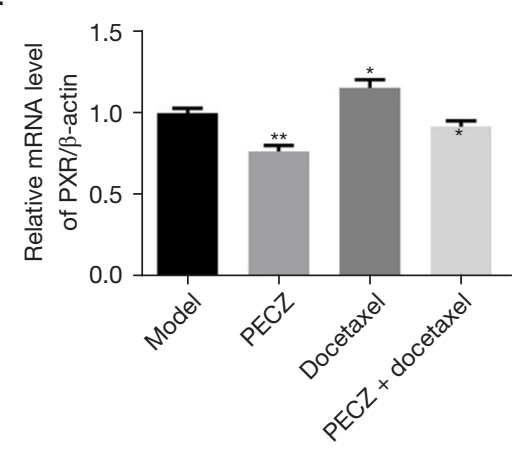

1

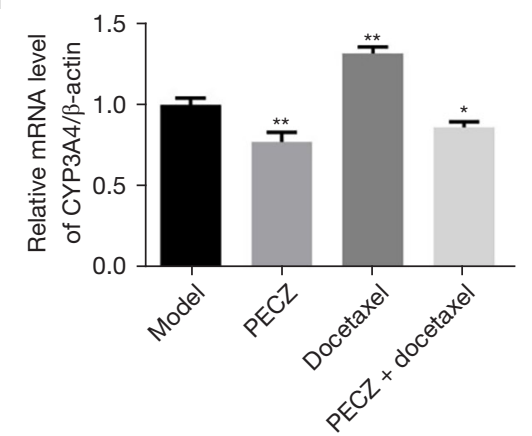

Figure 8 PECZ reduced the mRNA and protein expressions of drug resistance genes in tumor tissues. Effect of PECZ and docetaxel on the mRNA expressions of PXR (A), MDR1 (B), BCRP (C), and CYP3A4 (D) in tumor tissues. Representative band of each protein (E). Effect of PECZ and docetaxel on the protein expressions of PXR (F), MDR1 (G), BCRP $(\mathrm{H})$, and CYP3A4 (I) in tumor tissues. $(\bar{x} \pm s, \mathrm{n}=3)$; ${ }^{*}, \mathrm{P}<0.05$; **, $\mathrm{P}<0.01$ vs. model group. $\mathrm{PECZ}$, petroleum ether extracts of Curcuma zedoaria; $\mathrm{PXR}$, pregnane $\mathrm{X}$ receptor; MDR1, multidrug resistance 1 ; BCRP, breast cancer resistance protein; CYP3A4, cytochrome P-450.

inhibit the proliferation and reduce the expression of drug resistance genes of MDA-MB-231/docetaxel cells. Therefore, PECZ might be a potential drug for reversing docetaxel resistance, thereby providing a new therapeutic method for TNBC. Even though our data demonstrates that $\mathrm{PECZ}$ reverse the effect of docetaxel resistance in MDA-MB-231 cells, the effect of PECZ on the reversal of docetaxel resistance was not clear in other TNBC cells. Therefore, further study should be conducted to estimate effect of PECZ on docetaxel resistance.

\section{Acknowledgments}

Funding: The authors are grateful for the support from the Natural Science Program of Zhejiang Department of Finance (No. Y17H290001) and the Medical and Health Science and Technology Program of Zhejiang Province (No. 2021KY5172).

\section{Footnote}

Reporting Checklist: The authors have completed the 
ARRIVE reporting checklist. Available at https://dx.doi. org/10.21037/atm-21-4199

Data Sharing Statement: Available at https://dx.doi. org/10.21037/atm-21-4199

Conflicts of Interest: All authors have completed the ICMJE uniform disclosure form (available at https://dx.doi. org/10.21037/atm-21-4199). The authors have no conflicts of interest to declare.

Ethical Statement: The authors are accountable for all aspects of the work in ensuring that questions related to the accuracy or integrity of any part of the work are appropriately investigated and resolved. Experiments were performed under a project license [No.: SYXK (Zhe) 2020-0024] granted by ethics board of Hangzhou Eyong Biotechnological Co., Ltd. Animal Experiment Center, in compliance with National Institutes of Health Guide for the Care and Use of Laboratory Animals.

Open Access Statement: This is an Open Access article distributed in accordance with the Creative Commons Attribution-NonCommercial-NoDerivs 4.0 International License (CC BY-NC-ND 4.0), which permits the noncommercial replication and distribution of the article with the strict proviso that no changes or edits are made and the original work is properly cited (including links to both the formal publication through the relevant DOI and the license). See: https://creativecommons.org/licenses/by-nc-nd/4.0/.

\section{References}

1. Nakashima K, Uematsu T, Takahashi K, et al. Does breast cancer growth rate really depend on tumor subtype?

Measurement of tumor doubling time using serial ultrasonography between diagnosis and surgery. Breast Cancer 2019;26:206-14.

2. Jézéquel P, Kerdraon $\mathrm{O}$, Hondermarck $\mathrm{H}$, et al. Identification of three subtypes of triple-negative breast cancer with potential therapeutic implications. Breast Cancer Res 2019;21:65.

3. Wei W, Cao S, Liu J, et al. Fibroblast growth factor receptor 4 as a prognostic indicator in triple-negative breast cancer. Transl Cancer Res 2020;9:6881-8.

4. Harris AR, Perez MJ, Munson JM. Docetaxel facilitates lymphatic-tumor crosstalk to promote lymphangiogenesis and cancer progression. BMC Cancer 2018;18:718.
5. Najafi S, Payandeh M, Sadeghi M, et al. Phase II study of adjuvant docetaxel and carboplatin with/without doxorubicin and cyclophosphamide in triple negative breast cancer: a randomised controlled clinical trial. Contemp Oncol (Pozn) 2017;21:83-9.

6. Smalley M, Natarajan SK, Mondal J, et al. Nanoengineered Disruption of Heat Shock Protein 90 Targets Drug-Induced Resistance and Relieves Natural Killer Cell Suppression in Breast Cancer. Cancer Res 2020;80:5355-66.

7. Blackley EF, Loi S. Targeting immune pathways in breast cancer: review of the prognostic utility of TILs in early stage triple negative breast cancer (TNBC). Breast 2019;Suppl 1:S44-S48.

8. Wang K, Zhu X, Yin Y. Maslinic Acid Enhances Docetaxel Response in Human Docetaxel-Resistant Triple Negative Breast Carcinoma MDA-MB-231 Cells via Regulating MELK-FoxM1-ABCB1 Signaling Cascade. Front Pharmacol 2020;11:835.

9. Fulda S. Modulation of apoptosis by natural products for cancer therapy. Planta Med 2010;76:1075-9.

10. Nobili S, Lippi D, Witort E, et al. Natural compounds for cancer treatment and prevention. Pharmacol Res 2009;59:365-78.

11. Cui H, Zhang B, Li G, et al. Identification of a Quality Marker of Vinegar-Processed Curcuma Zedoaria on Oxidative Liver Injury. Molecules 2019;24:2073.

12. Gao XF, Li QL, Li HL, et al. Extracts from Curcuma zedoaria Inhibit Proliferation of Human Breast Cancer Cell MDA-MB-231 In Vitro. Evid Based Complement Alternat Med 2014;2014:730678.

13. Kastl L, Brown I, Schofield AC. Altered DNA methylation is associated with docetaxel resistance in human breast cancer cells. Int J Oncol 2010;36:1235-41.

14. Yi T, Zhai B, Yu Y, et al. Quantitative phosphoproteomic analysis reveals system-wide signaling pathways downstream of SDF-1/CXCR4 in breast cancer stem cells. Proc Natl Acad Sci U S A 2014;111:E2182-90.

15. Zhao S, Zuo WJ, Shao ZM, et al. Molecular subtypes and precision treatment of triple-negative breast cancer. Ann Transl Med 2020;8:499.

16. Maia AR, de Man J, Boon U, et al. Inhibition of the spindle assembly checkpoint kinase TTK enhances the efficacy of docetaxel in a triple-negative breast cancer model. Ann Oncol 2015;26:2180-92.

17. Hu Q, Chen WX, Zhong SL, et al. MicroRNA-452 contributes to the docetaxel resistance of breast cancer cells. Tumour Biol 2014;35:6327-34. 
18. Ayati Z, Ramezani M, Amiri MS, et al. Ethnobotany, Phytochemistry and Traditional Uses of Curcuma spp. and Pharmacological Profile of Two Important Species (C. longa and C. zedoaria): A Review. Curr Pharm Des 2019;25:871-935.

19. Mackowiak B, Hodge J, Stern S, et al. The Roles of Xenobiotic Receptors: Beyond Chemical Disposition. Drug Metab Dispos 2018;46:1361-71.

20. Shao Z, Li Y, Dai W, et al. ETS-1 induces Sorafenibresistance in hepatocellular carcinoma cells via regulating transcription factor activity of PXR. Pharmacol Res 2018;135:188-200.

21. Feng F, Jiang Q, Cao S, et al. Pregnane X receptor mediates sorafenib resistance in advanced hepatocellular carcinoma. Biochim Biophys Acta Gen Subj 2018;1862:1017-30.

22. Chen ZS, Tiwari AK. Multidrug resistance proteins (MRPs/ABCCs) in cancer chemotherapy and genetic diseases. FEBS J 2011;278:3226-45.

23. Kovalev AA, Tsvetaeva DA, Grudinskaja TV. Role of ABC-cassette transporters (MDR1, MRP1, BCRP) in

Cite this article as: Qiao EQ, Yang HJ, Yu XF, Gong LJ, Zhang XP, Chen DB. Curcuma zedoaria petroleum ether extract reverses the resistance of triple-negative breast cancer to docetaxel via pregnane $\mathrm{X}$ receptor. Ann Transl Med 2021;9(17):1389. doi: 10.21037/atm-21-4199 the development of primary and acquired multiple drug resistance in patients with early and metastatic breast cancer. Exp Oncol 2013;35:287-90.

24. Ring A, Kaur P, Lang JE. EP300 knockdown reduces cancer stem cell phenotype, tumor growth and metastasis in triple negative breast cancer. BMC Cancer 2020;20:1076.

25. Mandal A, Bisht R, Rupenthal ID, et al. Polymeric micelles for ocular drug delivery: From structural frameworks to recent preclinical studies. J Control Release 2017;248:96-116.

26. Li X, Wang G, Zhao J, et al. Antiproliferative effect of beta-elemene in chemoresistant ovarian carcinoma cells is mediated through arrest of the cell cycle at the G2-M phase. Cell Mol Life Sci 2005;62:894-904.

27. Li QQ, Wang G, Liang H, et al. $\beta$-Elemene promotes cisplatin-induced cell death in human bladder cancer and other carcinomas. Anticancer Res 2013;33:1421-8.

(English Language Editor: A. Kassem) 